BNL-113293-2016-JA

\title{
Ordering Pathway of Block Copolymers under Dynamic Thermal Gradients Studied by in situ GISAXS
}

\author{
Saumil Samant, Joseph Strzalka, Kevin G. Yager, \\ Kim Kisslinger, Danielle Grolman, Monali Basutkar, \\ Namrata Salunke, Gurpreet Singh, Brian Berry, Alamgir Karim
}

Submitted to Macromolecules

October 2016

Center for Functional Nanomaterials

Brookhaven National Laboratory

\author{
U.S. Department of Energy \\ USDOE Office of Science (SC), \\ Basic Energy Sciences (SC-22)
}

Notice: This manuscript has been authored by employees of Brookhaven Science Associates, LLC under Contract No. DE- SC0012704 with the U.S. Department of Energy. The publisher by accepting the manuscript for publication acknowledges that the United States Government retains a non-exclusive, paid-up, irrevocable, world-wide license to publish or reproduce the published form of this manuscript, or allow others to do so, for United States Government purposes. 


\section{DISCLAIMER}

This report was prepared as an account of work sponsored by an agency of the United States Government. Neither the United States Government nor any agency thereof, nor any of their employees, nor any of their contractors, subcontractors, or their employees, makes any warranty, express or implied, or assumes any legal liability or responsibility for the accuracy, completeness, or any third party's use or the results of such use of any information, apparatus, product, or process disclosed, or represents that its use would not infringe privately owned rights. Reference herein to any specific commercial product, process, or service by trade name, trademark, manufacturer, or otherwise, does not necessarily constitute or imply its endorsement, recommendation, or favoring by the United States Government or any agency thereof or its contractors or subcontractors. The views and opinions of authors expressed herein do not necessarily state or reflect those of the United States Government or any agency thereof. 


\section{Ordering Pathway of Block Copolymers under}

\section{Dynamic Thermal Gradients Studied by in situ}

\section{GISAXS}

Saumil Samant, ${ }^{\S \dagger}$ Joseph Strzalka, ${ }^{\S}$ Kevin G. Yager, ${ }^{\#}$ Kim Kisslinger, ${ }^{\#}$ Danielle Grolman, ${ }^{\S}$ Monali Basutkar, ${ }^{\S}$ Namrata Salunke, ${ }^{\S}$ Gurpreet Singh ${ }^{\S \dagger}$ Brian Berry $^{\$ \&}$, Alamgir Karim ${ }^{\S *}$

${ }^{\S}$ Department of Polymer Engineering, University of Akron, Akron, OH 44325, United States

${ }^{\$}$ X-Ray Science Division, Argonne National Laboratory, Argonne, Illinois 60439 , United States

${ }^{\#}$ Center for Functional Nanomaterials, Brookhaven National Laboratory, Upton, New York 11973, United States

${ }^{\$ S}$ Department of Chemistry, University of Arkansas, Little Rock, Arkansas, United States

KEYWORDS: cold zone annealing, block copolymer, GISAXS, in-situ, orientation correlation length 


\section{ABSTRACT}

Dynamic thermal gradient-based processes for directed self-assembly of block copolymer (BCP) thin films such as Cold Zone Annealing (CZA) have demonstrated much potential for rapidly fabricating highly ordered patterns of BCP domains with facile orientation control. As a demonstration, hexagonally packed predominantly vertical cylindrical morphology, technologically relevant for applications such as membranes and lithography, was achieved in $1 \mu \mathrm{m}$ thick cylinder-forming PS- $b$-PMMA (cBCP) films by applying sharp thermal gradients (CZA-Sharp) at optimum sample sweep rates. A thorough understanding of the molecular level mechanisms and pathways of the $\mathrm{BCP}$ ordering that occur during this CZA-S process is presented, useful to fully exploit the potential of CZA-S for large-scale BCP-based device fabrication. To that end, we developed a customized CZA-S assembly to probe the dynamic structure evolution and ordering of the PS- $b$-PMMA cBCP film in-situ as it undergoes the CZAS process using the Grazing Incidence Small Angle X-ray Scattering (GISAXS) technique. Four distinct regimes of $\mathrm{BCP}$ ordering were observed within the gradient that include microphase separation from an 'as cast' unordered state (Regime I), evolution of vertical cylinders under a thermally imposed strain gradient (Regime II), reorientation of a fraction of cylinders due to preferential substrate interactions (Regime III) and finally grain-coarsening on the cooling edge (Regime IV). The ordering pathway in the different regimes is further described within the framework of an energy landscape. A novel aspect of this study is the identification of a graincoarsening regime on the cooling edge of the gradient, previously obscure in zone annealing studies of BCPs. Such insights into the development of highly ordered BCP nanostructures under template-free thermal gradient fields can potentially have important ramifications in the field of BCP directed self-assembly and self-assembling polymer systems more broadly. 
Directed self-assembly of block copolymer (BCP) films with orientation control and macroscopic alignment is essential to realize the potential of BCP systems for next-generation applications. Particularly, fabrication of high aspect ratio vertically/horizontally oriented nanodomains of cylinder and lamellae forming BCPs with long-range order is attractive for capacitors, ${ }^{1}$ photonics, ${ }^{2}$ membranes ${ }^{3}$ and lithography ${ }^{4,5}$. Several efforts have been dedicated in the past couple of decades to induce the phase-separation and direct the self-assembly of BCP domains via force fields such as thermal ${ }^{6,7}$, solvent ${ }^{8,9}$, electrical ${ }^{10,11}$, magnetic ${ }^{12,13}$, shear ${ }^{14-16}$ as well as topographical patterning. ${ }^{17,18}$ Recently, dynamic thermal-gradient based processes such as Cold Zone Annealing ${ }^{6,14,19-22}$ (CZA) and Laser Zone Annealing ${ }^{23-26}$ (LZA) have evolved as potential techniques for rapid ordering of $\mathrm{BCP}$ films on template-free rigid and flexible substrates with excellent orientation control and roll-to-roll (R-2-R) compatibility. The basic idea behind zone annealing is to sweep samples across a temperature gradient, typically generated by a heating block flanked by cooling blocks on each side (CZA) or via a rastering laser line (LZA). The original zone-annealing concept arises from metallurgy and the semiconductor industry where moving thermal zones are used to process/purify metals and semiconductors by recrystallization and oriented grain growth. Lovinger $e t$ al. ${ }^{27}$ were among the first to apply zone annealing to polymers, where they studied the effect of a thermal gradient on the directional crystallization of Polyethylene oxide (PEO). Hashimoto and coworkers applied the zone-heating technique to order block copolymers, ${ }^{28,29}$ by passing BCP film samples across a cold block-hot block-cold block assembly, where the maximum temperature on the hot block was set above the order-disorder transition temperature $\left(\mathrm{T}_{\mathrm{ODT}}\right)$ of the $\mathrm{BCP}$ while the cold blocks were set much below the $\mathrm{T}_{\mathrm{ODT}}$, enabling temperature gradients up to $30^{\circ} \mathrm{C} / \mathrm{mm}$. Single-grain lamellar microdomains in bulk BCP were observed at sample sweep velocity of $25 \mathrm{~nm} / \mathrm{s}$, which was 
attributed to the propagation of lamellar grain growth at the disorder-order front along the gradient. However, this process is only applicable to BCPs with accessible ODTs below the degradation temperatures. Karim et.al modified this zone-heating technique and developed a "Cold" Zone Annealing (CZA) process for ordering BCP thin films much below the ODT. ${ }^{6}$ Applying gradients of $\sim 15^{\circ} \mathrm{C} / \mathrm{mm}$, they observed highly ordered striped patterns of horizontally oriented (parallel to substrate) cylindrical microdomains and demonstrated enhanced ordering kinetics as compared to conventional oven annealing in PS- $b$-PMMA cylinder-forming BCP (cBCP) thin films. ${ }^{30}$ Singh et.al further tuned the CZA process, by sharpening the temperature gradient to $45^{\circ} \mathrm{C} / \mathrm{mm}$ (CZA-Sharp) and observed that optimum sample sweep rates $(5-10 \mu \mathrm{m} / \mathrm{s})$ over sharp gradients resulted in highly oriented vertical cylinders with hexagonal packing. ${ }^{19}$

The present study is motivated by the fact that despite extensive combinatorial ex-situ studies on the ordering and orientation of various $\mathrm{BCP}$ and nanocomposite systems using the zone annealing process and its variants, ${ }^{6,19-22,28-31}$ the real-time or $i n-s i t u$ structure evolution along the gradient and associated molecular mechanisms and dynamics of $\mathrm{BCP}$ ordering during the process has not been studied. A few simulation studies have attempted to understand the structure evolution under thermal gradients, however the simulation length-scales fall short of replicating real experimental parameters. ${ }^{32,33}$ To design controllably ordered future BCP systems via CZA processing, it is essential to fully understand the molecular phenomena underlying the selfassembly and ordering of $\mathrm{BCP}$ structures within dynamic temperature gradients.

In this work, we demonstrate the first real-time study of $\mathrm{BCP}$ structure evolution and ordering dynamics of a model PS- $b$-PMMA cBCP under the sharp thermal gradient (CZA-S) process using in-situ Grazing Incidence Small Angle X-ray Scattering (GISAXS). GISAXS is an excellent tool for characterizing $\mathrm{BCP}$ nanostructures, including quantification of domain size, 
order and alignment in thin films. ${ }^{34-36}$ It has also been used recently to study BCP self-assembly in-situ, under processes such as solvent vapor annealing ${ }^{37,38}$. GISAXS provides volumeaveraged information over macroscopic distances within the sample as compared to the extremely localized information obtained from microscopy techniques. By tuning the grazing incidence angle below and above the polymer film critical angle $\left(\theta_{c}\right)$, one can probe the nearsurface and bulk film structure respectively. In addition, the fast data collection times (1-5 s) and the ability to track dynamic motion of the sample makes GISAXS a unique tool to study the insitu dynamic structure evolution, especially in the context of the CZA-S process.

To study the CZA-S process using GISAXS, we designed a customized CZA-S assembly, which can be directly mounted on to the sample stage at Beamline 8-ID-E at the Advanced Photon Source, Argonne National Laboratory. A schematic of the setup is shown in Figure 1. The design is based on the CZA-S setup of Singh et.al, ${ }^{19}$ consisting of a ceramic covered Ni-Cr resistive heating wire $(\mathrm{d}=3 \mathrm{~mm})$ flanked by aluminum cooling blocks fixed on a base steel plate. The details of the CZA-S setup are outlined in the Experimental section. Cylinder-forming PS- $b$-PMMA (35- $\left.b-12 \mathrm{~kg} \mathrm{~mol}^{-1}\right)$ films $(\sim 1 \mu \mathrm{m}$ thick) were coated on quartz substrates using a flow-coating technique. ${ }^{39}$ An optimum CZA-S sample sweep rate of $5 \mu \mathrm{m} / \mathrm{s}$ yields a high fraction of vertically oriented, hexagonally packed cylinders in thin $\mathrm{cBCP}$ films. ${ }^{19}$ This vertical cylindrical morphology is technologically relevant for applications in nanowire synthesis and membranes. Thus, we study the dynamic structure evolution of a cBCP at a sweep rate of $5 \mu \mathrm{m} / \mathrm{s}$. In a conventional CZA-S experiment, the samples are translated across the cold-hot-cold block assembly, while the assembly is fixed. Since the incident X-ray beam at the beamline has a fixed position, performing a conventional sample sweep would result in the X-rays probing different spots of the sample, at a fixed temperature position along the temperature gradient zone. 
However, for an in-situ study, it was essential that the X-ray beam tracked a single spot on the sample, as the spot was translated across the block assembly and experienced a complete thermal profile within the gradient. To achieve this, we used the concept of relative motions between the sample and the underlying assembly. The sample was translated at a CZA-S velocity $\mathrm{V}=+5$ $\mu \mathrm{m} / \mathrm{s}$ across the temperature gradient using a step-motor (model LS-65, PI miCos, Germany) that was attached on to the base steel plate, while simultaneously the beamline stage (model 5102.2, Huber, Germany) with the entire CZA-S assembly on top was precisely counter-translated in the opposite direction using an alternate motor with the opposite velocity $V=-5 \mu \mathrm{m} / \mathrm{s}$. The equal but opposite motion of the sample versus beamline stage ensures that the incident X-ray beam footprint (with slits $100 \mu \mathrm{m}$ horizontally $\times 50 \mu \mathrm{m}$ vertically, the footprint was $17 \mathrm{~mm}$ and fit entirely onto the sample, which was $25 \mathrm{~mm}$ in length along the beam direction) constantly probes a fixed spot on the sample, as the spot experiences the entire thermal profile along the temperature gradient. X-rays $(1.6868 \AA)$ impinged on the sample at incidence angle $\left(0.21^{\circ}\right)$ above the polymer critical angle $\left(\theta_{\mathrm{c}}=0.17^{\circ}\right)$ to probe the bulk film structure evolution. Data was captured every 50 seconds corresponding to $250 \mu \mathrm{m}$ of translation steps along the gradient zone from $60^{\circ} \mathrm{C}$ on the heating side to $83^{\circ} \mathrm{C}$ (below the $\mathrm{T}_{\mathrm{g}}$ of PS and PMMA blocks) on the cooling side as shown in inset of Figure 1. To avoid damage to the film due to X-ray beam at a single spot, the exposure time for each measurement was minimized $(0.2 \mathrm{~s})$.

\section{Experimental}

Film preparation: Diblock copolymer PS- $b$-PMMA $\left(M_{n}=47 \mathrm{~kg} \mathrm{~mol}^{-1}\right)$ was purchased from Polymer Source Inc. and used as received. The polymer was dissolved in toluene $(10 \% \mathrm{w} / \mathrm{w})$ and flow-coated ${ }^{39}$ onto UV-ozone cleaned quartz (GM Associates) slide $(76 \mathrm{~mm} \times 25 \mathrm{~mm} \times 1 \mathrm{~mm})$. 
Film thickness was measured using a Bruker DektakXT profilometer. Prior to processing, the film was dried in a vacuum oven at $65^{\circ} \mathrm{C}$ for 4 hours to remove residual solvent.

CZA-S processing and in-situ GISAXS: The CZA-S assembly consists of two hollow aluminum blocks with a ceramic covered $\mathrm{Ni}-\mathrm{Cr}$ resistance wire (3mm diameter) between them. For the present experiments, the blocks were fixed at a distance of $1 \mathrm{~mm}$ from the wire to establish a sharp thermal gradient. Both the blocks and the wire were mounted onto a base plate. The blocks were maintained at a temperature of about $26^{\circ} \mathrm{C}$ by circulating PDMS oil (Thermal C10 Julabo USA) using a chiller system (Julabo F12-ED refrigerated/heating circulator). The NiCr wire was heated using a high current source (Digital DC Power Supply, Model 1692, B\&K Precision) such that the maximum temperature $\left(\mathrm{T}_{\max }\right)$ on the gradient was about $205^{\circ} \mathrm{C}$. The temperature gradient thus produced $\left(\nabla \mathrm{T} \sim 45^{\circ} \mathrm{C} / \mathrm{mm}\right)$ was characterized using a thermal IR imaging camera having an accuracy of $0.1 \mathrm{C}$ (Testo 875 Thermal Imager Kit). The region of interest $\left(T_{\max }\right.$ to below $\left.T_{g}\right)$ on the thermal gradient profile was $8 \mathrm{~mm}$ wide. The base plate with the CZA-S assembly on top was mounted onto the beamline sample stage. The BCP film sample was placed on the CZA-S assembly and allowed to equilibrate while the thermal profile on the sample was monitored using an IR camera until the required gradient was established.

CZA-S processing was probed by in situ GISAXS at Beamline 8-ID-E ${ }^{40}$ at the Advanced Photon Source, operating with photon energy $7.35 \mathrm{keV}$ (X-ray wavelength $\lambda=1.6868 \AA$ ). A Pilatus 1M pixel array detector (Dectris, Switzerland) was positioned $2155 \mathrm{~mm}$ from the sample with a vacuum flight path spanning most of this length, except for an air gap approximately 270 $\mathrm{mm}$ in length to accommodate the sample and the CZA apparatus. The beamline sample stage (Model 5102.20, Huber Diffraktiontechnik, Germany) was equipped with a 20:1 gear reducer, allowing precise translation of the CZA-S cold- hot-cold block setup transverse to the beam over 
a total travel of $24 \mathrm{~mm}$. A second stage (Model LS-65, PI miCos, Germany) with $65 \mathrm{~mm}$ travel was mounted on the sample stage and used to pull the sample in the opposite direction with the same speed as the sample stage, thereby keeping the same region of the sample in the footprint of the X-ray beam. The driver for this stage (SINCOS, Phytron, Germany) was set for its maximum resolution, a 1/20 sinusoidal-shaped step, effectively providing a 20:1 gear reducer electronically. The translation stages were tested, timed via the EPICS interface and the translation verified with digital calipers. They were found to operate reliably down to a speed of $0.5 \mu \mathrm{m} / \mathrm{s}$, an order of magnitude slower than used for this study. The sample was positioned onto the CZA-S assembly in air with its short dimension $(25 \mathrm{~mm})$ along the direction of the beam and attached to the second stage with Kapton tape. A macro in Spec (Certified Scientific Software, Cambridge, MA) moved the two stages in the opposite direction at a speed of $5 \mu \mathrm{m} / \mathrm{s}$ in equal intervals (typically $0.250 \mathrm{~mm}$ apart) across the thermal gradient and paused at each interval to record exposures $(0.2 \mathrm{~s})$ with the pixel array detector over a range of incident angles $(\theta=0.15$, $\left.0.18,0.21^{\circ}\right)$ spanning the range from below the critical angle of the thin film $\left(0.17^{\circ}\right)$ to above it, but below the critical angle for the quartz substrate $\left(0.245^{\circ}\right)$. Data collection at each interval took less than 10 seconds including the time for motion of the incident angle stage, but the total exposure of the sample to the beam at each interval was $0.6 \mathrm{~s}$ ( 3 exposures of $0.2 \mathrm{~s} \mathrm{each)} \mathrm{a}$ shutter with sub-millisecond opening/closing time (model V09, AZsol, Switzerland) blocked the beam between exposures. A video camera mounted above the sample verified that the sample remained stationary with respect to reference marks and therefore also with respect to the X-ray beam during the measurements, within about $0.1 \mathrm{~mm}$, the width of the beam used in the measurement. GISAXS data were corrected for detector non-uniformity, efficiency and geometrical considerations and converted to q-space using the GIXSGUI ${ }^{41}$ package for Matlab 
(Mathworks, Natick, MA). Typically the data with $\theta=0.21^{\circ}$ showed the best contrast and were analyzed quantitatively. The results were independent of the number of intervals examined in the thermal gradient and the number of incident angles probed, indicating that the samples were not damaged by radiation exposure during the study. For example, for the data shown in Figure 2, the sample was probed at 32 intervals, with 3 incident angles at each interval for a total exposure time of $\sim 19 \mathrm{~s}$. Comparing data from the final interval with data from a previously unexposed part of the sample showed good agreement with the part of the sample studied in situ.

Microscopy: TEM samples of the film cross-section were made via the in-situ lift-out method using a FEI Helios 600 dual-beam FIB and imaged (brightfield) with a JEOL 1400 LAB6 TEM at $120 \mathrm{keV}$. Atomic Force Microscopy (AFM) micrographs of the surface topology were captured with a Veeco-Dimension Icon Atomic Force Microscope in the tapping mode. 


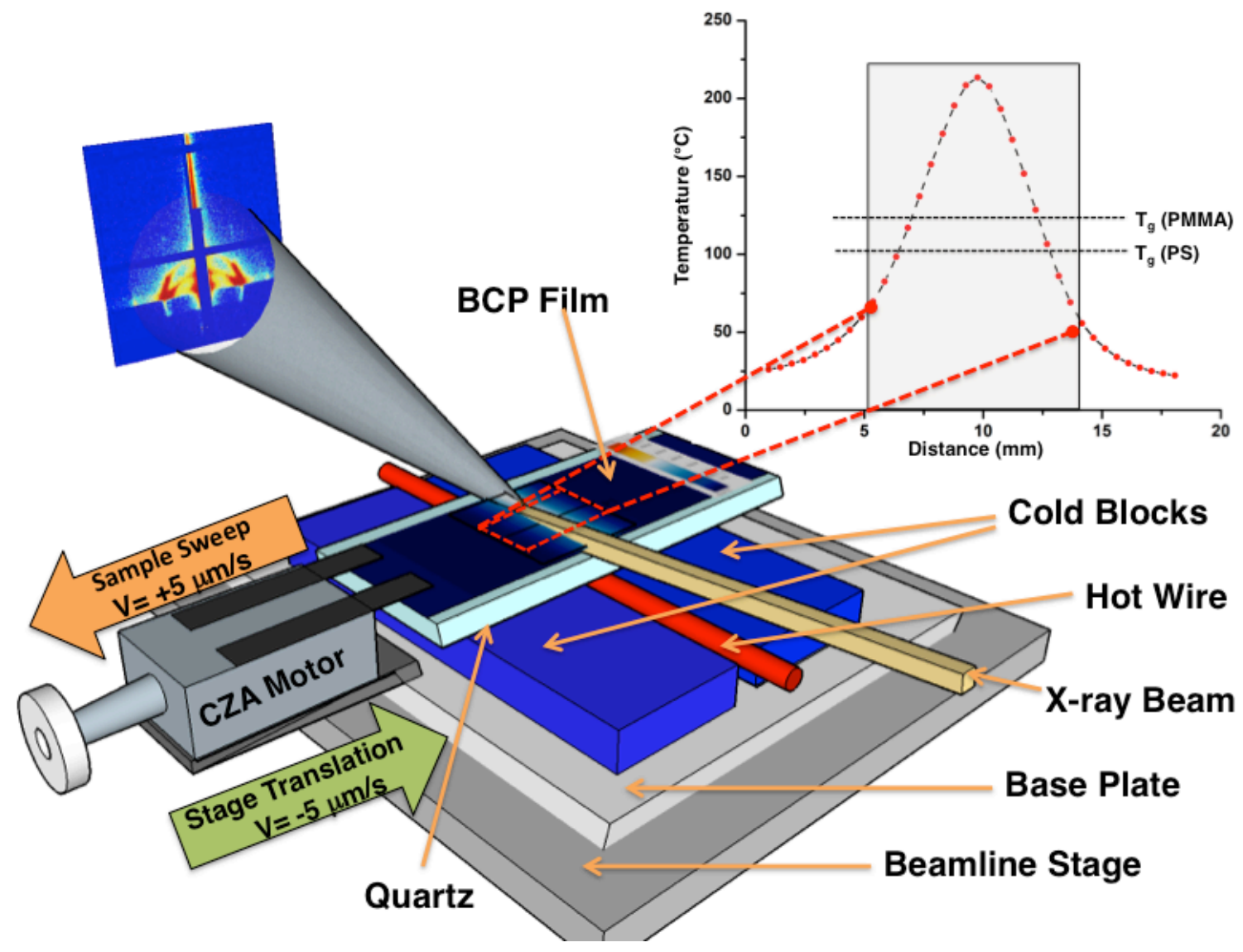

Figure 1. Schematic of CZA-S assembly developed for in-situ GISAXS experiments. The sample (cBCP film on quartz) is translated over the cold-hot-cold block CZA-S assembly using a step-motor at a velocity of $\mathrm{V}=+5 \mu \mathrm{m} / \mathrm{s}$, while simultaneously the beamline stage is counter translated in the opposite direction at a velocity of $-5 \mu \mathrm{m} / \mathrm{s}$ ensuring the X-ray beam probes a fixed spot across the temperature gradient. Inset: The CZA-S temperature gradient profile and region probed by GISAXS. 


\section{Results and Discussion}

The thermal profile on the BCP film sample kept over the CZA-S was captured using an IR camera, to establish the precise positional dependence of the temperature within the gradient. Using the GISAXS images and the thermal profile, we could accurately map the dynamic structure evolution of the $\mathrm{cBCP}$ film as it underwent the $\mathrm{CZA}-\mathrm{S}$ process from $60^{\circ} \mathrm{C}$ on the heating side to $83^{\circ} \mathrm{C}$ on the cooling side. Each data point could be precisely correlated with the temperature of the sample and the time under the CZA-S process, as indicated by the plot in Figure 2.

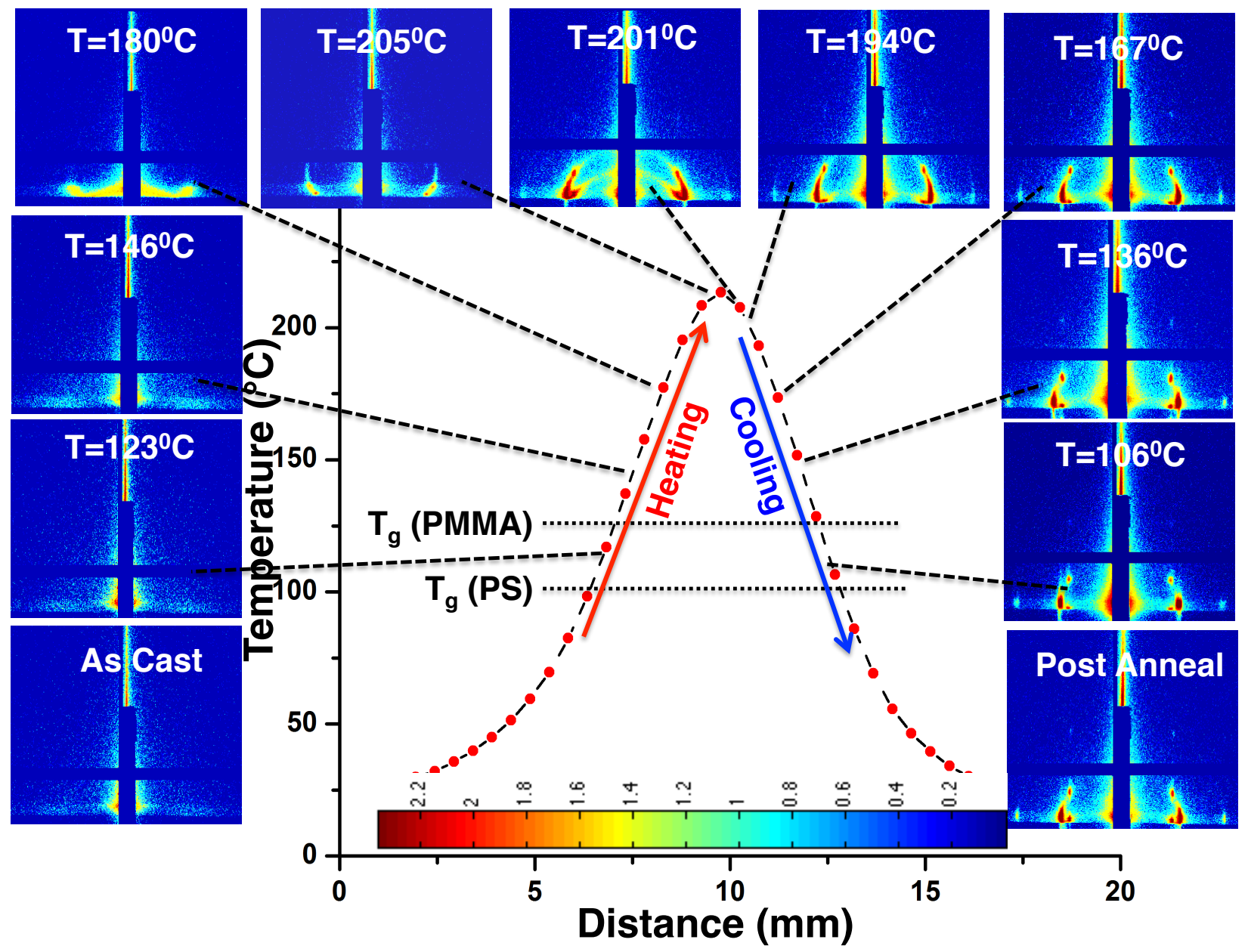

Figure 2. 2-dimensional GISAXS scattering patterns at incidence angle $0.21^{\circ}\left(\theta_{c}=0.17^{\circ}\right)$ showing in-situ nanostructure evolution of cylindrical PS- $b$-PMMA (35- $\left.b-12 \mathrm{~kg} \mathrm{~mol}^{-1}\right)$ film over 
the CZA-S temperature gradient $\left(\nabla \mathrm{T} \sim 45^{\circ} \mathrm{C} / \mathrm{mm}\right.$ ) at a translation speed of $5 \mu \mathrm{m} / \mathrm{s}$. The intensity scale (log scale) is constant for all images as indicated.

A distinct evolution of the BCP film structure from the unordered as-cast state to the wellordered cylindrical microdomain structure occurs over the temperature range spanned. The relevant measure of time for the self-assembly and ordering process in CZA-S is regarded as the time spent by the sample above the $T_{\mathrm{g}}$ of both blocks, which for the current PS- $b$-PMMA system is the time spent by the sample above $126^{\circ} \mathrm{C}$ ( $\mathrm{T}_{\mathrm{g}}$, PMMA $)$. To quantify the GISAXS data, we obtain integrated intensity line cuts along the sample plane $\left(\mathrm{q}_{\mathrm{x}}\right)$ at $\mathrm{q}_{\mathrm{z}}=0.024 \AA^{-1}$ for each GISAXS image and plot the line cuts with respect to the CZA-S time $\left(\mathrm{T}_{\mathrm{g}}\right.$-to- $\left.\mathrm{T}_{\mathrm{g}}\right)$ and corresponding temperature, as shown in Figure 3. The intensities of the line cuts are scaled arbitrarily to demonstrate the evolution of structure. Four regimes of ordering are observed for the CZA-S spanned temperature range as described.

Regime I) Unordered State: The as-cast $1 \mu \mathrm{m}$ thick sample shows a very weak scattering pattern indicating a poorly ordered film. Such a structure can be attributed to kinetically trapped microphase separation due to rapid solvent evaporation during the flow coating process. As the sample enters the heating zone on the gradient, we do not observe appreciable changes in the structure until it crosses the $\mathrm{T}_{\mathrm{g}}$ of both PS $\left(\mathrm{T}_{\mathrm{g}} \sim 107^{\circ} \mathrm{C}\right)$ and PMMA $\left(\mathrm{T}_{\mathrm{g}} \sim 126^{\circ} \mathrm{C}\right)$ components. Above $150^{\circ} \mathrm{C}$, we begin to observe changes in the scattering pattern; a very weak, broad Bragg peak $\left(\mathrm{q}_{\mathrm{x}}=0.03 \AA^{-1}\right)$ is seen at $\sim 168^{\circ} \mathrm{C}$ indicating evolution of PMMA cylindrical microdomains within the PS matrix.

Regime II) Initially Ordered State: As the sample moves further in to the sharp gradient heating zone, the Bragg peak shifts to $\mathrm{q}_{\mathrm{x}}=0.0267 \AA^{-1}$ giving a lattice spacing of $23.5 \mathrm{~nm}$, very close to the bulk lattice spacing $(23.8 \mathrm{~nm})$ for the current PS- $b$-PMMA $\left(35-b-12 \mathrm{~kg} \mathrm{~mol}^{-1}\right)$ system, as 
seen in the inset of Figure 3. The peak also starts to become sharper and more intense, suggesting ordering of the microphase separated PMMA cylindrical microdomains.

Regime III) Polygrain State: When the sample crosses the sharp zone and reaches $\mathrm{T}_{\max } \sim 205^{\circ} \mathrm{C}$, two additional Bragg peaks at $\mathrm{q}_{\mathrm{x}}=0.023 \AA^{-1}$ and $\mathrm{q}_{\mathrm{x}}=0.045 \AA^{-1}$ emerge in the scattering pattern. The ratio of peaks at $\mathrm{q}_{\mathrm{x}}=0.023 \AA^{-1}$ and $\mathrm{q}_{\mathrm{x}}=0.026 \AA^{-1}$ suggests a bimodal cylindrical morphology, that is a coexistence of vertically and horizontally oriented cylinders. ${ }^{42} \mathrm{We}$ confirm this bimodal orientation, by indexing the peak positions of the post-annealed cylindrical structure to a 2-dimensional hexagonal lattice as shown in Figure 4a and in Supporting Information Figure S2. The peak at $\mathrm{q}_{\mathrm{x}}=0.023 \AA^{-1}$ represents the horizontally oriented hexagonal packed cylinders and gives the cylinder-to-cylinder spacing of $\sim 27.5 \mathrm{~nm}$, while the peaks at $\mathrm{q}_{\mathrm{x}}=0.026$ $\AA^{-1}$ and $\mathrm{q}_{\mathrm{x}}=0.045 \AA^{-1}$ represent the (01) and higher order (11) reflections of the vertically oriented hexagonal packed cylindrical lattice structure. Additionally, we also observe intense isotropic rings emerging from both $\mathrm{q}_{\mathrm{x}}=0.023 \AA^{-1}$ and $\mathrm{q}_{\mathrm{x}}=0.026 \AA^{-1}$ in the GISAXS pattern. The isotropic rings indicate a polygrain structure consisting of small regions (grains) with a broad range of different orientations.

Regime IV) Highly Ordered State with Grain-growth: As the sample further crosses $T_{\max }$ and enters the cooling zone, the isotropic ring structure begins to diminish and the Bragg peaks become sharper, suggesting that cylinder grains become well-aligned (into the horizontal or vertical configurations), as well as enhancement in the correlation length (i.e. grain growth). Contrary to previous assumptions in zone annealing of $\mathrm{BCPs}$, that the order evolves completely on the heating side of the gradient and the cooling zone merely plays the role of freezing the structure, here we demonstrate that the cooling zone plays an essential role in the ordering of the BCP through a grain-growth mechanism. The peak width sharpens until the sample reaches a 
temperature of about $137^{\circ} \mathrm{C}$ on the cooling zone, following which the scattering pattern does not differ significantly, and ultimately the structure is quenched as the temperature falls below the $\mathrm{T}_{\mathrm{g}}$ of both blocks.

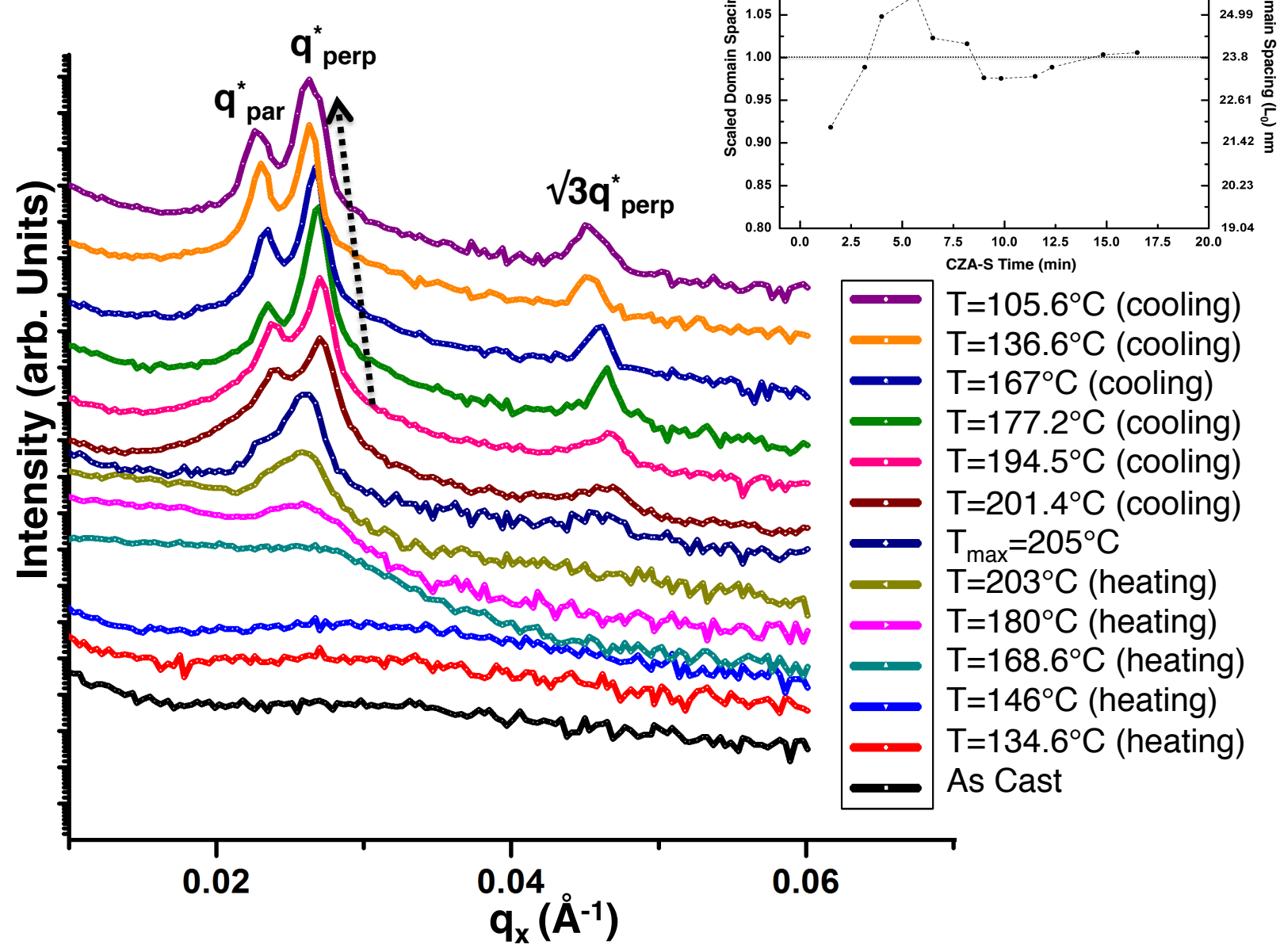

Figure 3. 1-Dimensional integrated intensity profiles (taken along $\mathrm{q}_{\mathrm{x}}$ at $\mathrm{q}_{\mathrm{z}}=0.024 \AA^{-1}$ ) of in-situ GISAXS scattering patterns of PS- $b$-PMMA (35- $\left.b-12 \mathrm{~kg} \mathrm{~mol}^{-1}\right)$ film under CZA-S $(\mathrm{V}=5 \mu \mathrm{m} / \mathrm{s}$ and $\nabla \mathrm{T} \sim 45^{\circ} \mathrm{C} / \mathrm{mm}$ ) as a function of CZA-S time and temperature. The profile intensities are offset for clarity. Inset: Plot of variation of domain spacing $\left(\mathrm{L}_{0}\right)$ within the CZA-S temperature gradient as obtained from the intensity profiles (The dotted line indicates bulk domain spacing). 
As the cylindrical microstructure evolves, we also observe a shift of peak positions towards lower q values in Regime IV as indicated by the arrow in Figure 3. This can be attributed to the variation of $\chi$ within the CZA-S temperature gradient (see Supporting Information Figure S1). We observe that on the cooling side of the CZA-S temperature curve, the $\chi$ value for our system increases from 0.036568 to 0.038504 as the temperature decreases from $205^{\circ} \mathrm{C}\left(\mathrm{T}_{\max }\right)$ to $113^{\circ} \mathrm{C}$ (calculated based on reference 43). For our BCP system $\mathrm{N}=460.9$, therefore, $16.85<\chi \mathrm{N}<17.75$ on the cooling side. This corresponds to an intermediate segregation regime ${ }^{44}$ for which $\mathrm{L}_{0} \sim \chi^{\mathrm{a}}$ (astatistical segment length). Thus, as temperature decreases, $\chi$ increases and the peak positions undergo shifting towards lower q (higher $\mathrm{L}_{0}$ ).

The highly ordered hexagonal packing of vertical cylindrical microdomains is confirmed using AFM measurements at the surface of the film as shown in Figure 4.b as well as GISAXS data below the critical angle (Supporting Information Figure S3). The FFT of the AFM micrograph, shown in the inset of Figure 4.b indicates the hexagonal lattice structure of the vertical cylinders. Cross-sectional TEM imaging of the CZA-S processed films, show an ordered cylindrical structure with highly oriented vertical cylinders throughout the $1 \mu \mathrm{m}$ thick film (Figure 4.c) and a small fraction of horizontal cylinders near the substrate surface (inset of Figure 4.c), thus confirming the bimodal orientation. Such template-free high degree of vertical ordering of cylinders in thick films is comparable to previous observations in thin film cylindrical BCP systems. ${ }^{7,45-47}$ 

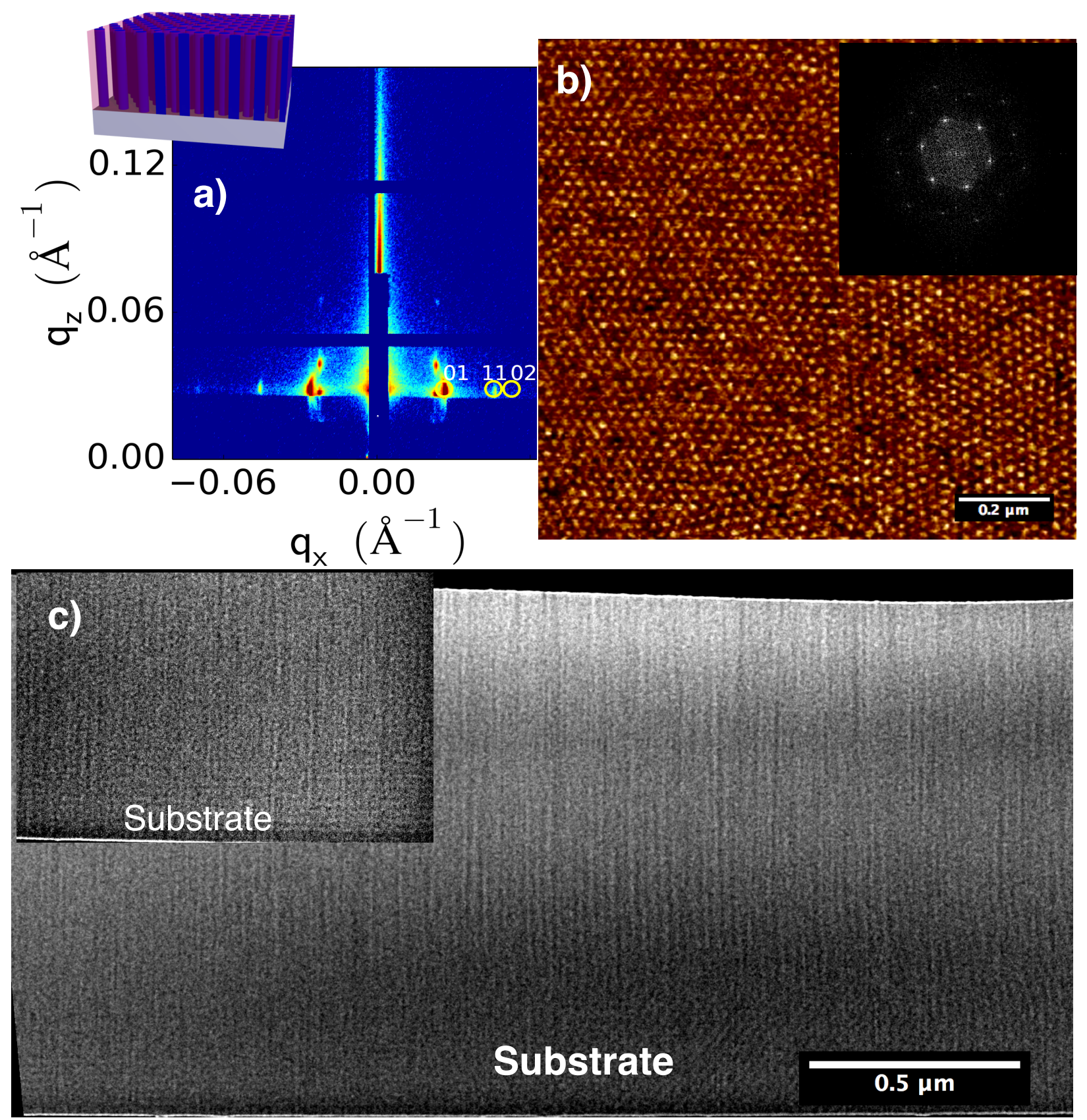

Figure 4. Hexagonally packed cylindrical morphology of PS- $b$-PMMA (35-b-12 $\left.\mathrm{kg} \mathrm{mol}^{-1}\right) \mathrm{cBCP}$ film with bimodal orientation after CZA-S process. a) 2-dimensional GISAXS image indexed to a hexagonal lattice with a lattice spacing of $23.8 \mathrm{~nm}$ (oriented with cylinder axes out-of-plane, as shown in overlay). The peak positions account for the refraction-induced distortion inherent to GISAXS. b) Surface topography AFM micrograph (inset: FFT). c) Cross-sectional TEM image 
of the film showing bimodal cylinder orientation. Inset: Area near the substrate showing parallel cylinder orientation.

To quantify the ordering and explain the evolution of the vertical cylindrical structure in different zones along the gradient, we track the evolution of the Bragg peak at $\mathrm{q}_{\mathrm{x}}=0.026 \AA^{-1}$ corresponding to the vertical cylindrical morphology. By obtaining fits to the GISAXS intensity curves (Supporting Information Figure S4) the peak widths in terms of full width at halfmaximum (fwhm) are calculated (Supporting Information Figure S5). In order to estimate the correlation length $\xi$ (typical lengthscale over which the self-assembled morphology has conserved orientational and positional order), we perform Scherrer analysis (Equations 1 and 2) on the peak widths. To account for the grazing-incidence experimental geometry we subtract the broadening contributions arising due to the x-ray energy bandwidth, the instrumental beam divergence, the detector pixel size, and the geometrical spread of the beam along the sample (i.e. along the beam direction) due to the grazing geometry. ${ }^{48}$

$$
\begin{aligned}
\xi & =\frac{2 \pi K}{\Delta q} \\
\Delta q & =\frac{4 \pi}{\lambda} \cos (\theta) \frac{B}{2}
\end{aligned}
$$

where $\mathrm{B}$ is the width of Bragg peak (fwhm), $2 \theta$ is the scattering angle, $\lambda$ is the wavelength of $\mathrm{X}$ rays used $(1.6868 \AA)$ and $\mathrm{K}$ is the Scherrer constant $(\approx 0.94)$. A plot showing the evolution of correlation lengths (scaled with respect to bulk $\mathrm{L}_{0}$ ) and corresponding schematics of morphology evolution, as the film is swept across the CZA-S temperature gradient, is shown in Figure 5. We note that this naïve Scherrer analysis-interpreting the inverse peak width as the correlation length for order-has its limitations. The Scherrer equation is most valid in the limit of well- 
defined crystallinity truncated by sharp grain boundaries. Block copolymers exhibit a variety of disorder contributions, including grain boundaries, point defects, lattice fluctuations, and 'meandering' of the morphology. In this work we use (corrected) peak width as an estimate of the correlation length. This assumption should thus yield correct trends in correlation length (i.e. relative ordering lenthscales between different measurements), up to an unknown constant.

Next, we correlate the GISAXS scattering patterns and the correlation lengths with the morphology within the four distinct ordering regimes in the CZA-S process. In Regime I, the kinetically trapped cylinder structure in the as-cast state begins to microphase separate due to the mobility imparted by the temperature rise above the $T_{g}$ of both blocks. Regime I extends until the sample reaches about $168^{\circ} \mathrm{C}$ on the gradient, where microphase separated PMMA cylinders with average domain spacing $\sim 23.5 \mathrm{~nm}$ (bulk $\mathrm{L}_{0}=23.8 \mathrm{~nm}$ ) are formed. The width of the Bragg peak in this regime is fairly large which likely result from a mixture of different orientations of poorly developed cylinder spacing with ill-defined grains. In Regime II $\left(168^{\circ} \mathrm{C}-200^{\circ} \mathrm{C}\right)$, we observe a distinct evolution of the morphology to a polygrain structure of hexagonally packed vertical cylinders, which is attributed to the sharp thermal gradient within the film. As postulated by Singh et.al,${ }^{19}$ the sharp thermal gradient leads to a normal (to substrate) thermal expansion of the film, resulting in an imposed vertical strain gradient. This strain gradient drives the formation of vertical cylinders over horizontal cylinders as the natural geometry to relieve the stresses imposed by the boundaries of the expanded film region. In a conventional (oven) thermal annealing process for the PS- $b$-PMMA system, the preferential wetting of the PMMA over the native-oxide covered quartz and polymer relaxation over long annealing times are competing factors that favor a horizontal (parallel to substrate) orientation of the microdomains over vertical ordering. However, for a CZA-S sweep performed in the velocity range $5-15 \mu \mathrm{m} / \mathrm{s}$, the normal 
expansion-induced strain gradient dominates over preferential wetting and the annealing times (above $\mathrm{T}_{\mathrm{g}}$ ) are lower than typical polymer relaxation time, ${ }^{19,49}$ leading to a strong bias for vertical orientation of the PMMA cylinders.

As the sample further traverses the gradient and approaches $T_{\max }$, it exits the sharp gradient zone and enters a broad temperature gradient zone extending from about $200^{\circ} \mathrm{C}$ on the heating side up to $200^{\circ} \mathrm{C}$ on the cooling side. This zone is Regime III, where the sample resides for about 200s. In this broad gradient zone, the preferential (PMMA) substrate wetting-induced ordering dominates leading to horizontally oriented cylinders near the substrate as indicated by the peak at $\mathrm{q}_{\mathrm{x}}=0.023 \AA^{-1}$ and confirmed by the cross-sectional TEM images in Figure 4.c. However, the extent of propagation of horizontal ordering in the film thickness direction is a function of the strength of substrate-PMMA block interactions and typically extends up to $6-8 \mathrm{~L}_{0}$ within the film. ${ }^{50}$ Hence, despite the reorientation near the substrate, a majority of the film thickness retains the vertical ordering due to the previously imposed vertical strain gradient. Thus, the film attains a bimodal orientation of cylinders, with horizontal cylinders near the substrate surface and vertical cylinders near the air interface. We note that a weaker PS attraction to the air boundary is insufficient to form parallel cylinders at the air boundary. These observations are in good agreement with previous CZA-S results on thin $\mathrm{cBCP}$ films and thus corroborate the previously postulated mechanism of vertical cylinder formation in CZA-S.

Next, the sample moves in to the sharp zone again, but on the cooling side of the gradient. In this Regime IV $\left(200^{\circ} \mathrm{C}-137^{\circ} \mathrm{C}\right)$, a rapid growth in the in-plane orientation correlation length $(\xi)$ of vertically ordered cylinder domains is observed (Figure 5). A noteworthy highlight of this insitu work is the identification of this correlation-length growth regime, which has not been previously explored in zone annealing studies of BCPs. In conventional thermal annealing of 
BCP systems, the correlation length dynamics are a function of the annealing temperature, annealing time and film thickness. ${ }^{7,51,52}$ It has been shown that $\xi$ increases with increasing annealing time ( $\mathrm{t})$ and temperature. At a given annealing temperature, the correlation length scales with time according to a power law $\left(\xi \sim \mathrm{t}^{\mathrm{n}}\right) \cdot{ }^{51}$ Correlation lengths on the order of $300 \mathrm{~nm}$ $500 \mathrm{~nm}$ have been obtained for hexagonally packed vertical cylinders in surface studies of very thin $(30 \mathrm{~nm}-100 \mathrm{~nm})$ films of cBCPs, annealed for $10^{3}-10^{5} \mathrm{~s}$ on surface modified (random brush grafted) substrates. ${ }^{7,47,51,52}$ However, as the film thickness increases beyond $300 \mathrm{~nm}$, the effect of the surface modification within the bulk of the film reduces, leading to changes in the orientation of the cylinders, mismatch of cylindrical structures ${ }^{49}$ and rapidly falling $\xi^{47}$. It is noteworthy that the correlation lengths $(\sim 200 \mathrm{~nm})$ obtained here using CZA-S are for a much $(\sim 3 \mathrm{x})$ thicker film $(\sim 1 \mu \mathrm{m})$ but comparable to previous studies on grain coarsening in vertically oriented thin $\mathrm{cBCP}$ films using conventional thermal annealing. In fact, the comparable correlation lengths are achieved at much faster rates ( $\sim 700 \mathrm{~s})$ and on unmodified (non-grafted) substrates using the CZA-S process. We believe that the grain coarsening seen on the cooling side of the CZA-S gradient in Regime IV is related to the increasing interaction parameter $(\chi)$. As seen in Figure 5, initial ordering takes place from $T_{g}$ upto $T_{\max }$ and thereafter early stage of vitrification is observed from $\mathrm{T}_{\max }\left(205^{\circ} \mathrm{C}\right)$ till about $160^{\circ} \mathrm{C}$. In this phase, as the temperature decreases, it leads to an increase in the Flory-Huggins interaction parameter between PS and PMMA (since $\chi$ $\sim 1 / T)^{49}$ as shown in Supporting Information Figure S.1. Therefore, vitrification kinetics coupled with an increasing interaction parameter in Regime IV leads to an increased correlation length and grain coarsening. Beyond the Regime IV, as the sample moves below $\sim 137^{\circ} \mathrm{C}$ on the cooling side, the correlation length reaches a plateau. As the sample approaches the $T_{g}$, the 
reduced mobility of polymer chains considerably slows down the grain-growth dynamics and the film shows no appreciable changes in the ordered cylindrical structure as it is cooled below $T_{g}$.
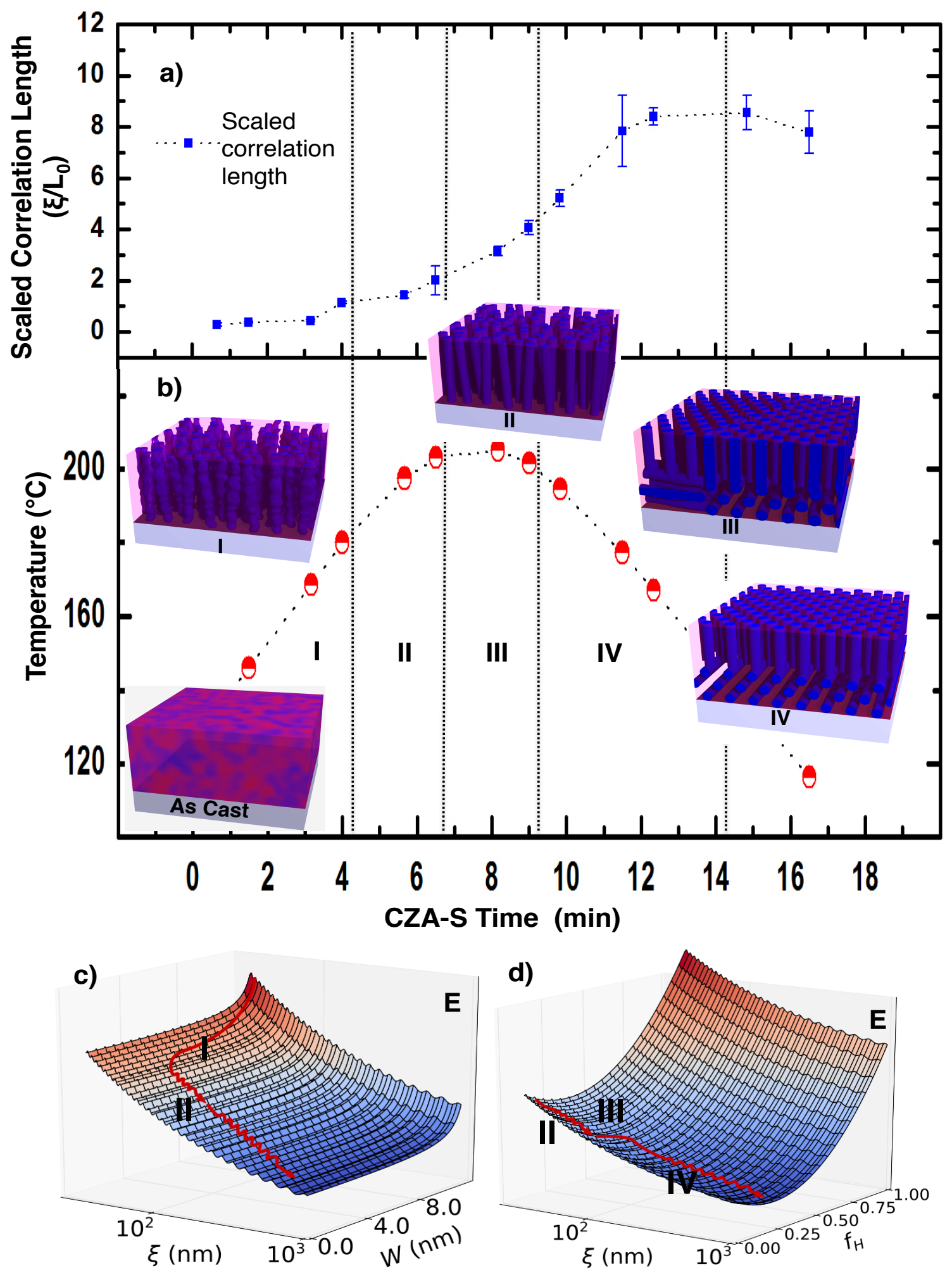
Figure 5. Regimes of $\mathrm{cBCP}$ ordering within $\mathrm{CZA}-\mathrm{S}$ temperature gradient. Plot showing the evolution of a) scaled orientation correlation length $\left(\xi / \mathrm{L}_{0}\right)$ of vertically oriented hexagonally packed cylinders of PS- $b$-PMMA (35- $\left.b-12 \mathrm{~kg} \mathrm{~mol}^{-1}\right)$ film with respect to b) CZA-S annealing time and corresponding temperature within the gradient. Energy landscape schematic of regime based pathway of ordering of cBCP within the CZA-S gradient in c) Regime I and II and d) Regime II, III and IV. The phase separation is characterized by the interfacial width $W$, while the average morphology orientation is characterized by $f_{H}$ (the fraction of cylinders adopting a horizontal, instead of vertical, orientation). The dynamic history of CZA processing selects a particular ordering pathway through the energy landscape (red lines).

The evolution of structure in the film can be considered in the context of the energy landscape of the BCP morphology (Figure 5.c, d). In general, two energetic terms can be regarded as contributing to the ordering process. The first term relates to the microphase separation of the kinetically trapped film structure and subsequent sharpening of the interfaces between the blocks. Using the interrelation between the interaction parameter $(\chi)$, temperature $(\mathrm{T})$ and the width of the interface (W), Yager et al. have described the temperature required to thermally broaden the interfaces to a width W (Equation 3). They postulated an energetic term of the form ' $k_{B} \mathrm{~T}$ ' describing the energy for microphase separation via interfacial sharpening. ${ }^{24}$

$$
T=\frac{\chi_{\mathrm{H}}}{\left(\frac{a^{2}}{6 W^{2}}-\chi_{\mathrm{S}}\right)}
$$

where $\chi_{\mathrm{H}}$ and $\chi_{\mathrm{S}}$ are the enthalpic and entropic contributions to the interaction parameter and ' $\mathrm{a}$ ' is the statistical segment length. 
The second energy term represents the contribution to the energy from annihilation of morphological defects such as point defects and grain boundaries during ordering. Kim et al. have studied the thermodynamic and kinetic aspects of defectivity in BCP thin films. ${ }^{49}$ Elimination of a single defect involves a pathway with 1-4 barriers, each incurring a penalty of 1-20 $k_{B} \mathrm{~T}$. The defect density $\left(\rho_{\mathrm{d}}\right)$ has an inverse relation with the orientation correlation length $\left[\rho_{\mathrm{d}} \sim 2 /\left(\mathrm{L}_{0} \xi\right)\right]$; so the energy penalty for BCP morphology with a certain number of defects can be calculated. ${ }^{24}$

In general, annealing causes the self-assembling BCP to descend the energy landscape towards the minimum (equilibrium). In oven annealing, ordering involves rapid phase separation (Regime I) and slow grain coarsening (Regime IV). It is frequently observed in self-assembly that the system becomes kinetically trapped in some part of the energy landscape, due to the numerous energy barriers for defect elimination. Zone annealing, on the other hand, is a dynamic processing method that can influence the pathway taken through the self-assembly energy landscape. In Regime III, in the broad zone we observe that a fraction of the cylinders near the substrate undergo reorientation from vertical to horizontal to form a more stable bimodal morphology. Due to the difference in the surface energies of the PS and PMMA blocks and affinity of PMMA toward the native oxide layer on the quartz substrate, preferential substrate surface wetting of PMMA block occurs to attain thermodynamic equilibrium in the system. For this effect, we postulate another energetic term of the parabolic form $\mathrm{E} \sim\left(\mathrm{f}_{\mathrm{H}}-\mathrm{f}_{\mathrm{Heq}}\right)^{2}$ where $\mathrm{f}_{\mathrm{H}}$ is the fraction of horizontal cylinders and $\mathrm{f}_{\mathrm{Heq}}$ is equilibrium orientation ratio for the given CZA-S conditions. Block copolymers are strongly sensitive to the relative orientation of the mesophase with respect to nearby boundaries. The chemical makeup of interfaces (which enforce particular wetting conditions), and the sizescale of confinement (which influences the relative stability of 
orientations based on commensurability match to the $\mathrm{BCP}$ repeat-distance) both influence the relative energies of different morphology orientations. Thus, the equilibrium orientation distribution is system-specific, being influenced by film thickness, wetting conditions, and the block copolymer materials themselves. In our system, to a first order approximation, we obtain an orientation ratio of 90:10 for the vertical: horizontal orientation fraction by comparing the area under the GISAXS intensity curves from the fits to the peaks corresponding to respective orientations. Thus, combining the three energetic terms for the CZA-S conditions explored here, the energy pathway follows a rapid evolution of vertical cylinders in Regimes I and II, followed by a shift towards a bimodal morphology with a sharp orientation distribution (predominantly vertically-aligned) in Regime III and finally development of orientation correlation lengths through grain coarsening in Regime IV.

Thus, the in-situ study of the structure evolution of BCP under the CZA-S process provides valuable insight into the ordering mechanism and dynamics of the process. It yields information about the effect of different zones within the temperature gradient on the orientation of microdomains and the correlation length coarsening dynamics. This new knowledge of the different ordering regimes can provide a molecular level understanding to tune the CZA-S process to achieve specific morphologies, orientations or larger grain sizes. For instance, the fact that coarsening occurs on the cooling side of the gradient motivates us to consider an asymmetric gradient with a sharp heating side but a shallow cooling side in the future. Besides, a number of other CZA-S process variants for target morphologies with novel BCP materials can be envisioned utilizing the regime-based ordering pathways within controlled thermal gradients. 


\section{Conclusions}

We have developed a technique to probe the real-time structure evolution and dynamics of block copolymer (BCP) ordering in films under thermal gradient fields using in-situ GISAXS. By combining surface probe microscopy and cross-sectional TEM with the integrated intensity profiles and curve fits to the GISAXS data, four distinct regimes of ordering were identified for a cBCP ordering: Regime I where ordering initiates from a kinetically trapped unordered state with interfacial sharpening; Regime II characterized by evolution of vertical cylinders due to thermally imposed strain-gradient; Regime III where reorientation of a fraction of cylinders near the substrate due to preferential wetting effect occurs in the broad gradient zone; and, Regime IV where cooling gradient enhances the final correlation-length to create large grain growth. The pathway of ordering through the four regimes was explained in the context of an energy landscape for the $\mathrm{BCP}$ morphology. The identification of these regimes, in particular the grain coarsening in Regime IV is a novel accomplishment of this in-situ work, which previous ex-situ studies on BCP ordering under thermal gradients could not establish.

An important result is that a predominantly vertical, hexagonally packed cylindrical morphology with a sharp orientation distribution throughout a $1 \mu \mathrm{m}$ thick film is obtained for the CZA-S conditions explored here. Orientation correlation lengths comparable to oven annealing are achieved at much faster rates and without the need for grafting substrates with random copolymer brushes. With increasing technological inclination toward the fabrication of high aspect ratio vertical domains of BCPs with controlled lateral order, these fundamental results on the dynamics of order evolution can have important implications for future BCP film processing methods using template free approaches. 


\section{Supporting Information.}

Graph showing variation of $\chi$ within CZA-S gradient, indexing of peaks to hexagonal lattice showing parallel cylinders, surface GISAXS image of post CZA-S sample, example of curve fitting to the 1-dimensional GISAXS integrated intensity profiles to obtain peak widths (fwhm) and orientation correlation lengths, plot of peak widths with respect to CZA-S temperature and time (PDF)

\section{AUTHOR INFORMATION}

\section{Corresponding Author}

* Email: alamgir@uakron.edu

\section{Present Addresses}

$\dagger$ Intel Corporation, 2501 NW 229th Ave, Hillsboro, Oregon 97124, USA

\section{Funding Sources}

This work was supported by the National Science Foundation (NSF) via Grant DMR- 1411046.

\section{ACKNOWLEDGMENT}

Research carried out at the Advanced Photon Source, is supported by the U.S. Department of Energy (DOE) Office of Science User, under Contract No. DE-AC02-06CH11357. Research carried out at the Center for Functional Nanomaterials is supported by the U.S. Department of Energy, Office of Basic Energy Sciences, under Contract No. DE-SC0012704. The authors are 
grateful to Ed Laughlin for help with fabricating the customized CZA-S assembly. S.P.S. would also like to acknowledge Xiao Zhang and Arvind Modi for their contributions.

\section{REFERENCES}

(1) Samant, S. P.; Grabowski, C. A.; Kisslinger, K.; Yager, K. G.; Yuan, G.; Satija, S. K.;

Durstock, M. F.; Raghavan, D.; Karim, A. Directed Self-Assembly of Block Copolymers for High Breakdown Strength Polymer Film Capacitors. ACS Appl. Mater. Interfaces 2016, 8, 7966-7976.

(2) Kang, Y.; Walish, J. J.; Gorishnyy, T.; Thomas, E. L. Broad-Wavelength-Range Chemically Tunable Block-Copolymer Photonic Gels. Nat. Mater. 2007, 6, 957-960.

(3) Phillip, W. A.; O’Neill, B.; Rodwogin, M.; Hillmyer, M. A.; Cussler, E. L. SelfAssembled Block Copolymer Thin Films as Water Filtration Membranes. ACS Appl. Mater. Interfaces 2010, 2, 847-853.

(4) Hawker, C. J.; Russell, T. P. Block Copolymer Lithography: Merging "Bottom-Up" with “Top-Down” Processes. MRS Bull. 2005, 30, 952-966.

(5) Ruiz, R.; Kang, H.; Detcheverry, F. A.; Dobisz, E.; Kercher, D. S.; Albrecht, T. R.; de Pablo, J. J.; Nealey, P. F. Density Multiplication and Improved Lithography by Directed Block Copolymer Assembly. Science (80-. ). 2008, 321, 936-939.

(6) Berry, B. C.; Bosse, A. W.; Douglas, J. F.; Jones, R. L.; Karim, A. Orientational Order in Block Copolymer Films Zone Annealed below the Order-Disorder Transition Temperature. Nano Lett. 2007, 7, 2789-2794. 
(7) Ji, S.; Liu, C.-C.; Liao, W.; Fenske, A. L.; Craig, G. S. W.; Nealey, P. F. Domain Orientation and Grain Coarsening in Cylinder-Forming Poly(styrene- B -Methyl Methacrylate) Films. Macromolecules 2011, 44, 4291-4300.

(8) Sinturel, C.; Vayer, M.; Morris, M.; Hillmyer, M. A. Solvent Vapor Annealing of Block Polymer Thin Films. Macromolecules 2013, 46, 5399-5415.

(9) Modi, A.; Bhaway, S. M.; Vogt, B. D.; Douglas, J. F.; Al-Enizi, A.; Elzatahry, A.; Sharma, A.; Karim, A. Direct Immersion Annealing of Thin Block Copolymer Films. ACS Appl. Mater. Interfaces 2015, 7, 21639-21645.

(10) Böker, A.; Knoll, A.; Elbs, H.; Abetz, V.; Müller, A. H. E.; Krausch, G. Large Scale Domain Alignment of a Block Copolymer from Solution Using Electric Fields. Macromolecules 2002, 35, 1319-1325.

(11) Thurn-Albrecht, T.; DeRouchey, J.; Russell, T. P.; Kolb, R. Pathways toward Electric Field Induced Alignment of Block Copolymers. Macromolecules 2002, 35, 8106-8110.

(12) Majewski, P. W.; Gopinadhan, M.; Osuji, C. O. Magnetic Field Alignment of Block Copolymers and Polymer Nanocomposites: Scalable Microstructure Control in Functional Soft Materials. J. Polym. Sci. Part B Polym. Phys. 2012, 50, $2-8$.

(13) Gopinadhan, M.; Majewski, P. W.; Choo, Y.; Osuji, C. O. Order-Disorder Transition and Alignment Dynamics of a Block Copolymer Under High Magnetic Fields by In Situ XRay Scattering. Phys. Rev. Lett. 2013, 110, 78301.

(14) Singh, G.; Yager, K. G.; Berry, B.; Kim, H. C.; Karim, A. Dynamic Thermal FieldInduced Gradient Soft-Shear for Highly Oriented Block Copolymer Thin Films. ACS 
Nano 2012, 6, 10335-10342.

(15) Chen, Z. Pathways to Macroscale Order in Nanostructured Block Copolymers. Science (80). 1997, 277, 1248-1253.

(16) Angelescu, D. E.; Waller, J. H.; Adamson, D. H.; Deshpande, P.; Chou, S. Y.; Register, R. A.; Chaikin, P. M. Macroscopic Orientation of Block Copolymer Cylinders in SingleLayer Films by Shearing. Adv. Mater. 2004, 16, 1736-1740.

(17) Cheng, J. Y.; Mayes, A. M.; Ross, C. A. Nanostructure Engineering by Templated SelfAssembly of Block Copolymers. Nat. Mater. 2004, 3, 823-828.

(18) Edwards, E. W.; Montague, M. F.; Solak, H. H.; Hawker, C. J.; Nealey, P. F. Precise Control over Molecular Dimensions of Block-Copolymer Domains Using the Interfacial Energy of Chemically Nanopatterned Substrates. Adv. Mater. 2004, 16, 1315-1319.

(19) Singh, G.; Yager, K. G.; Smilgies, D.-M.; Kulkarni, M. M.; Bucknall, D. G.; Karim, A. Tuning Molecular Relaxation for Vertical Orientation in Cylindrical Block Copolymer Films via Sharp Dynamic Zone Annealing. Macromolecules 2012, 45, 7107-7117.

(20) Singh, G.; Batra, S.; Zhang, R.; Yuan, H.; Yager, K. G.; Cakmak, M.; Berry, B.; Karim, A. Large-Scale Roll-to-Roll Fabrication of Vertically Oriented Block Copolymer Thin Films. ACS Nano 2013, 7, 5291-5299.

(21) Samant, S.; Hailu, S. T.; Al-Enizi, A. M.; Karim, A.; Raghavan, D. Orientation Control in Nanoparticle Filled Block Copolymer Cold Zone Annealed Films. J. Polym. Sci. Part B Polym. Phys. 2015, 53, 604-614.

(22) Ye, C.; Sun, Y.; Karim, A.; Vogt, B. D. Extending Dynamic Range of Block Copolymer 
Ordering with Rotational Cold Zone Annealing (RCZA) and Ionic Liquids. Macromolecules 2015, 48, 7567-7573.

(23) Majewski, P. W.; Yager, K. G. Millisecond Ordering of Block Copolymer Films via Photothermal Gradients. ACS Nano 2015, 9, 3896-3906.

(24) Majewski, P. W.; Yager, K. G. Latent Alignment in Pathway-Dependent Ordering of Block Copolymer Thin Films. Nano Lett. 2015, 15, 5221-5228.

(25) Majewski, P. W.; Yager, K. G. Block Copolymer Response to Photothermal Stress Fields. Macromolecules 2015, 150702153518002.

(26) Majewski, P. W.; Rahman, A.; Black, C. T.; Yager, K. G. Arbitrary Lattice Symmetries via Block Copolymer Nanomeshes. Nat. Commun. 2015, 6, 7448.

(27) Lovinger, A. J.; Gryte, C. C. The Morphology of Directionally Solidified Poly(ethylene Oxide) Spherulites. Macromolecules 1976, 9, 247-253.

(28) Bodycomb, J.; Funaki, Y.; Kimishima, K.; Hashimoto, T. Single-Grain Lamellar Microdomain from a Diblock Copolymer. Macromolecules 1999, 32, 2075-2077.

(29) Mita, K.; Tanaka, H.; Saijo, K.; Takenaka, M.; Hashimoto, T. Cylindrical Domains of Block Copolymers Developed via Ordering under Moving Temperature Gradient. Macromolecules 2007, 40, 5923-5933.

(30) Yager, K. G.; Fredin, N. J.; Zhang, X.; Berry, B. C.; Karim, A.; Jones, R. L. Evolution of Block-Copolymer Order through a Moving Thermal Zone. Soft Matter 2010, 6, 92-99.

(31) Berry, B. C.; Singh, G.; Kim, H.-C.; Karim, A. Highly Aligned Block Copolymer Thin 
Films by Synergistic Coupling of Static Graphoepitaxy and Dynamic Thermal Annealing Fields. ACS Macro Lett. 2013, 2, 346-350.

(32) Bosse, A.; Douglas, J.; Berry, B.; Jones, R.; Karim, A. Block-Copolymer Ordering with a Spatiotemporally Heterogeneous Mobility. Phys. Rev. Lett. 2007, 99, 216101.

(33) Cong, Z.; Zhang, L.; Wang, L.; Lin, J. Understanding the Ordering Mechanisms of SelfAssembled Nanostructures of Block Copolymers during Zone Annealing. J. Chem. Phys. 2016, $144,114901$.

(34) Müller-Buschbaum, P. GISAXS and GISANS as Metrology Technique for Understanding the 3D Morphology of Block Copolymer Thin Films. Eur. Polym. J. 2016.

(35) Müller-Buschbaum, P. Grazing Incidence Small-Angle X-Ray Scattering: An Advanced Scattering Technique for the Investigation of Nanostructured Polymer Films. Anal. Bioanal. Chem. 2003, 376, 3-10.

(36) Lee, B.; Park, I.; Yoon, J.; Park, S.; Kim, J.; Kim, K.; Chang, T.; Ree, M. Structural Analysis of Block Copolymer Thin Films with Grazing Incidence Small-Angle X-Ray Scattering. Macromolecules 2005, 38, 4311-4323.

Gu, X.; Gunkel, I.; Hexemer, A.; Gu, W.; Russell, T. P. An in Situ Grazing Incidence XRay Scattering Study of Block Copolymer Thin Films during Solvent Vapor Annealing. Adv. Mater. 2014, 26, 273-281.

(38) Zhang, J.; Posselt, D.; Smilgies, D. M.; Perlich, J.; Kyriakos, K.; Jaksch, S.; Papadakis, C. M. Lamellar Diblock Copolymer Thin Films during Solvent Vapor Annealing Studied by Gisaxs: Different Behavior of Parallel and Perpendicular Lamellae. Macromolecules 
2014, 47, 5711-5718.

(39) Stafford, C. M.; Roskov, K. E.; Epps, T. H.; Fasolka, M. J. Generating Thickness Gradients of Thin Polymer Films via Flow Coating. Rev. Sci. Instrum. 2006, 77, 23908.

(40) Jiang, Z.; Li, X.; Strzalka, J.; Sprung, M.; Sun, T.; Sandy, A. R.; Narayanan, S.; Lee, D. R.; Wang, J. The Dedicated High-Resolution Grazing-Incidence X-Ray Scattering Beamline 8-ID-E at the Advanced Photon Source. J. Synchrotron Radiat. 2012, 19, 627636.

(41) Jiang, Z. GIXSGUI : A MATLAB Toolbox for Grazing-Incidence X-Ray Scattering Data Visualization and Reduction, and Indexing of Buried Three-Dimensional Periodic Nanostructured Films. J. Appl. Crystallogr. 2015, 48, 917-926.

(42) Gong, J.; Ahn, H.; Kim, E.; Lee, H.; Park, S.; Lee, M.; Lee, S.; Kim, T.; Kwak, E.-A.; Ryu, D. Y. Rapid Structural Reorganization in Thin Films of Block Copolymer SelfAssembly. Soft Matter 2012, 8, 3570.

(43) Russell, T. P.; Hjelm, R. P.; Seeger, P. A. Temperature Dependence of the Interaction Parameter of Polystyrene and Poly(methyl Methacrylate). Macromolecules 1990, 23, 890893.

(44) Matsen, M. W.; Bates, F. S. Block Copolymer Microstructures in the IntermediateSegregation Regime. J. Chem. Phys. 1997, 106.

(45) She, M.-S.; Lo, T.-Y.; Ho, R.-M. Long-Range Ordering of Block Copolymer Cylinders Driven by Combining Thermal Annealing and Substrate Functionalization. ACS Nano 2013, 7, 2000-2011. 
(46) Han, E.; Stuen, K. O.; Leolukman, M.; Liu, C.-C.; Nealey, P. F.; Gopalan, P. Perpendicular Orientation of Domains in Cylinder-Forming Block Copolymer Thick Films by Controlled Interfacial Interactions. Macromolecules 2009, 42, 4896-4901.

(47) Ferrarese Lupi, F.; Giammaria, T. J.; Volpe, F. G.; Lotto, F.; Seguini, G.; Pivac, B.; Laus, M.; Perego, M. High Aspect Ratio PS-B-PMMA Block Copolymer Masks for Lithographic Applications. ACS Appl. Mater. Interfaces 2014, 6, 21389-21396.

(48) Smilgies, D. M. Scherrer Grain-Size Analysis Adapted to Grazing-Incidence Scattering with Area Detectors. J. Appl. Crystallogr. 2009, 42, 1030-1034.

(49) Beaucage, G.; Banach, M. J.; Vaia, R. A. Relaxation of Polymer Thin Films in Isothermal Temperature-Jump Measurements. J. Polym. Sci. Part B Polym. Phys. 2000, 38, 29292936.

(50) Xu, T.; Hawker, C. J.; Russell, T. P. Interfacial Interaction Dependence of Microdomain Orientation in Diblock Copolymer Thin Films. Macromolecules 2005, 38, 2802-2805.

(51) Ruiz, R.; Bosworth, J. K.; Black, C. T. Effect of Structural Anisotropy on the Coarsening Kinetics of Diblock Copolymer Striped Patterns. Phys. Rev. B - Condens. Matter Mater. Phys. 2008, 77, 1-5.

(52) Black, C. T.; Guarini, K. W. Structural Evolution of Cylindrical-Phase Diblock Copolymer Thin Films. J. Polym. Sci. Part A Polym. Chem. 2004, 42, 1970-1975. 
For Table of Contents use only

\section{Ordering Pathway of Block Copolymers under Dynamic}

\section{Thermal Gradients Studied by in situ GISAXS}

Saumil Samant, ${ }^{\S \dagger}$ Joseph Strzalka, ${ }^{\$}$ Kevin G. Yager, ${ }^{\#}$ Kim Kisslinger, ${ }^{*}$ Danielle Grolman, ${ }^{\S}$

Monali Basutkar, ${ }^{\S}$ Namrata Salunke, ${ }^{\S}$ Gurpreet Singh, ${ }^{\S \dagger}$ Brian Berry ${ }^{\$ \$}$, Alamgir Karim ${ }^{\S} *$

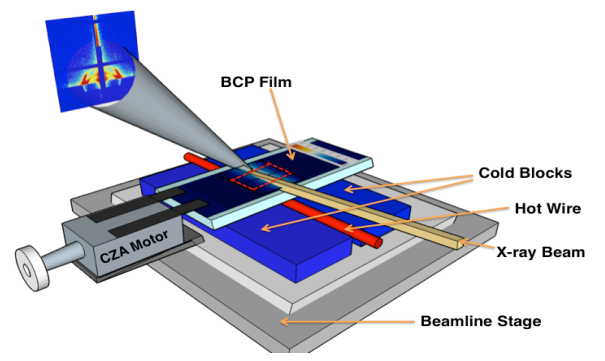

